\title{
Interlocuções teóricas nos estudos de gênero: um estudo de caso sob o prisma da complexidade
}

\author{
Benedito Gomes Bezerra* \\ Renato Lira Pimentel ${ }^{* *}$
}

\begin{abstract}
Resumo: Considerando a atual centralidade dos estudos de gênero, o objetivo deste artigo é investigar como se caracterizou, do ponto de vista teórico, a pesquisa de gênero no Nordeste brasileiro, a partir de dois programas de pós-graduação em que esses estudos se destacaram nas últimas décadas. Foi analisado, sob a ótica da complexidade, um corpus de 86 dissertações e teses, observando-se nelas os autores e teorias mobilizados e os diálogos teóricos efetivados. Os resultados sugerem que os estudos de gênero no Nordeste tanto absorvem teorias exógenas, como encetam diálogos entre aportes teóricos diversos, caracterizando-se pela heterogeneidade, dinamicidade e não linearidade.
\end{abstract}

Palavras-chave: Estudos de gênero. Teorias de gênero. Complexidade. Interlocuções teóricas.

\begin{abstract}
Considering the current centrality of genre studies, the aim of this work is to investigate how, from a theoretical point of view, genre research in Northeast Brazil was characterized, based on two graduate programs in which these studies stood out in the last decades. It was analyzed, from the perspective of complexity, a corpus of 86 theses and dissertations, observing in them the authors and theories mobilized and the theoretical dialogues carried out. The results suggest that genre studies in the Northeast both absorb exogenous theories and initiate dialogues between different theoretical contributions, characterized by heterogeneity, dynamics and non-linearity.
\end{abstract}

Keywords: Genre studies. Genre theory. Complexity. Theoretical interlocutions.

Resumen: Considerando la centralidad actual de los estudios de género, el objetivo de este artículo es investigar cómo, desde un punto de vista teórico, se caracterizó la investigación de género en el noreste de Brasil, en base a dos programas de posgrado en los que estos estudios se destacaron en las últimas décadas. Se analizó, desde la perspectiva de la complejidad, un corpus de 86 disertaciones y tesis, observando en ellas los autores y teorías movilizados y los diálogos teóricos realizados. Los resultados sugieren que los estudios de género en el noreste absorben

\footnotetext{
* Professor da Universidade de Pernambuco (UPE), Campus Mata Norte, e da Universidade Católica de Pernambuco (UNICAP). http://orcid.org/000o-0002-7382-0937

${ }^{* *}$ Professor da Universidade de Pernambuco (UPE), Campus Garanhuns. http://orcid.org/oooo-00024409-5545
}

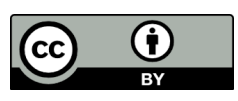

Este artigo está licenciado sob forma de uma licença Creative Commons Atribuição 4.0 Internacional, que permite uso irrestrito, distribuição e reprodução em qualquer meio, desde que a publicação original seja corretamente citada. https://creativecommons.org/licenses/by/4.0/deed.pt_BR. 
teorías exógenas e inician diálogos entre diferentes contribuciones teóricas, caracterizadas por la heterogeneidad, la dinámica y la no linealidad.

Palabras clave: Estudios de género. Teorías de género. Complexidad. Interlocuciones teóricas.

\section{Introdução}

As discussões sobre gênero textual tornaram-se tema central já há alguns anos entre os linguistas brasileiros, principalmente no que se refere ao trabalho com a diversidade de gêneros nas aulas de língua materna ou estrangeira. Muitos centros de pesquisa espalhados por todo o país têm se dedicado a entender a complexidade do fenômeno dos gêneros e de como eles medeiam e organizam as diversas práticas comunicativas através das diferentes ações sociais que realizam. Desse modo, tem-se como resultado uma grande quantidade de teses, dissertações, monografias e artigos científicos a esse respeito.

Ao passo que muitas e diferentes pesquisas são desenvolvidas sobre essa temática, diferentes teorias também são discutidas e utilizadas para proceder com uma diversidade de análises, bem como para o desenvolvimento de metodologias de ensino que possibilitem a aprendizagem significativa por meio dos gêneros. Dentre as teorias mais utilizadas aqui no Brasil, por exemplo, estão aquelas ligadas à Linguística Sistêmico Funcional (LSF), ao Inglês para Fins Específicos (ESP, do inglês English for Specific Purposes), aos Estudos Retóricos de Gênero (ERG) e ao Interacionismo Sociodiscursivo (ISD).

Entendendo que a noção de gênero pode ser compreendida à luz de diferentes perspectivas teóricas, percebe-se que as diferentes abordagens sobre esse fenômeno, no cenário brasileiro, podem aparecer isoladas, associadas entre si ou ainda associadas a teorias que em princípio não teriam o gênero como foco primário (BEZERRA, 2017), formando assim um quadro bastante heterogêneo. A partir dessa percepção, surgiram discussões sobre a utilização das diferentes teorias e sobre as interlocuções teóricas construídas nas pesquisas desenvolvidas no país.

Seguindo essa linha de reflexão, alguns estudiosos fizeram referência a uma "síntese brasileira” para descrever o conjunto de pesquisas desenvolvidas no contexto 
nacional (BAWARSHI; REIFF, 2013). Embora a reflexão sobre a síntese brasileira seja relativamente recente, após as discussões estabelecidas no VIII Simpósio Internacional de Estudos de Gênero Textual (SIGET) na Universidade de São Paulo (USP), em 2015, entendeu-se que essa ideia deve ser vista como simplificadora, dada a diversidade que compõe a realidade de estudos nos diferentes centros de pesquisa brasileiros (DOLZ, 2016; BAZERMAN, 2016). Dessa maneira, entende-se que os diferentes diálogos entre teorias de gênero precisam ser analisados de modo plural e levando em consideração a mesclagem de teorias e a sua organização no desenvolvimento das pesquisas, a exemplo de como perceberam Bezerra (2016) e Pimentel e Lêdo (2016).

Neste artigo, nosso objetivo é investigar como se caracterizaram, do ponto de vista da apropriação e dos diálogos entre teorias, os estudos de gênero no Nordeste brasileiro, a partir de dois programas de pós-graduação (PPGs) em que esses estudos entraram com força já no início dos anos de 2000. Analisamos 86 teses e dissertações do Programa de Pós-Graduação em Letras da Universidade Federal de Pernambuco (UFPE) e do Programa de Pós-Graduação em Linguística da Universidade Federal do Ceará (UFC), defendidas entre os anos de 2000 e 2016. O critério de escolha desses programas foi sua menção, por Marcuschi (2008), como integrantes do restrito grupo dos principais centros nacionais de irradiação de estudos de gênero no início da primeira década do século XXI. De acordo com Marcuschi (2008), o Programa da UFPE estaria associado a uma perspectiva "mais geral" e o da UFC, a uma abordagem "swalesiana" dos estudos de gênero.

Compreendendo os gêneros, assim como a interlocução que se estabelece entre as teorias de gênero nas pesquisas brasileiras, como fenômenos complexos, adotamos aportes da Teoria da Complexidade como base epistemológica para pensarmos essa interlocução. Assim, o primeiro tópico do trabalho tratará desse aporte teóricoepistemológico. Em seguida, explicitaremos nosso entendimento do que sejam diálogos e sínteses no que diz respeito às relações entre teorias de gênero adotadas na pesquisa brasileira. No último tópico, analisaremos como se deram tais diálogos ou interlocuções teóricas nas pesquisas desenvolvidas nos PPGs de Letras da UFPE e Linguística da UFC no recorte temporal anunciado acima. 


\section{Recepção das teorias de gênero sob a ótica da Teoria da Complexidade}

Nesta seção, apresentamos algumas considerações sobre os aspectos que envolvem o paradigma da complexidade, que será tratado como um aparato teóricoepistemológico para o enquadramento de nosso objeto de estudo. Na área da Linguística, alguns autores já desenvolveram estudos que levam em consideração os preceitos da complexidade em sua relação com a linguagem. Larsen-Freeman (1997) é a primeira dentre esses autores, sendo que as concepções da estudiosa foram exploradas em detalhe no livro publicado com Lynn Cameron (LARSEN-FREEMAN; CAMERON, 20o8). No Brasil, apenas a título de ilustração, a coletânea publicada por Vera Lúcia Menezes de Oliveira e Paiva e Milton Nascimento (PAIVA; NASCIMENTO, 2011) apresenta uma diversidade de estudos em Linguística Aplicada que adotam a concepção de língua e linguagem como sistemas complexos. Os estudos sobre gêneros, especificamente, são vistos como fenômeno complexo por Vian Jr. (2015).

A Teoria da Complexidade (TC), como defendida por Edgar Morin, surgiu como proposta de um novo paradigma epistemológico que caracterizou a segunda metade do século XX. Na ótica da complexidade, propunha-se uma forma diferente de pensar a natureza do conhecimento científico, na forma de uma crítica radical ao saber fragmentado, característico do modelo cartesiano que dominava o desenvolvimento científico desde o século XVII. A TC, dessa forma, é mais bem compreendida sob ótica dessa crítica à fragmentação do saber, em contraposição à qual ela procura assegurar as condições para o estabelecimento de um novo paradigma.

É nessa linha de reflexão, pensando numa crítica ao paradigma mestre e numa discussão que envolve a caracterização da atividade do pensamento que se concentra a TC. Para Morin (1986), a atividade do pensamento se caracteriza por distinção, objetivação, análise e seleção. Assim, podem ser percebidas distinções principalmente entre objetos e meios. A objetivação é a caracterização do objeto por meio de traços invariantes ou estáveis. A análise é a decomposição do objeto em suas unidades constitutivas e a possibilidade de isolar um objeto ou parte do objeto. Por fim, a seleção 
representa uma escolha dos caracteres julgados essenciais ou pertinentes ao objeto considerado.

Desse modo, Morin (1986) concentra sua crítica em possíveis desvios que tais passos implicaram para o modelo cartesiano, considerando a inevitabilidade destas operações. Para o estudioso, a distinção se torna disjunção quando se separam e se isolam entidades (fenômenos, processos), sem fazer com que se comuniquem, quando se exclui o aspecto oposto como se fosse inexistente. O que fundamenta esta operação é justamente o “princípio da separação” de René Descartes, que é o recurso para o conhecimento objetivo pretendido, separando-se os objetos uns dos outros, do seu ambiente e do sujeito conhecedor. A disjunção "dissocia e separa o que, sem dúvida, deve ser distinguido e oposto, mas é também inseparável e complementar: a ordem e a desordem, o determinismo e a liberdade, a repetição e a inovação [...] a sociedade e o indivíduo" (MORIN, 1986, p. 119).

A TC distingue e analisa, de acordo com o paradigma anterior, mas busca estabelecer a comunicação entre o que se distingue: o objeto, o ambiente, a coisa observada e o seu observador. Nesse aspecto, não pode existir um pensamento linear, que imponha hegemonicamente uma lógica em que não se contemplem contradições e desordens. Segundo Morin (2008), o paradigma do pensamento complexo não "produz" nem "determina" a inteligibilidade. $\mathrm{O}$ autor defende que esse paradigma pode incitar a estratégia/inteligência do sujeito pesquisador a considerar a complexidade da temática que está sendo estudada. Pode também incitar "a distinguir e fazer comunicar em vez de isolar e separar, a reconhecer os traços singulares, originais, históricos do fenômeno em vez de ligá-los pura e simplesmente a determinações ou leis gerais" (MORIN, 2008, p. 334). Desse modo, ao incitar o pesquisador a se dar conta dos aspectos multidimensionais de toda realidade em que se propõem pesquisas, o paradigma da complexidade "concebe a unidade/multiplicidade de toda entidade em vez de a heterogeneizar em categorias separadas ou de a homogeneizar em indistinta totalidade (MORIN, 2008, p. 334). 


\section{Sobre diálogos entre teorias nos estudos de gêneros}

Os diálogos e as interlocuções entre teorias podem ser considerados como possibilidades inerentes a todo trabalho acadêmico, inclusive em pesquisas nos níveis de mestrado e de doutorado. O diálogo entre teorias é parte importante da pesquisa científica porque contribui para imprimir-lhe consistência, principalmente esse diálogo resulta na discussão de como os autores-fontes evocados complementam-se, intercomunicam-se ou mesmo contradizem-se. $\mathrm{Na}$ pesquisa em Linguística, especificamente nos trabalhos sobre gêneros, isso não é diferente. Uma vez que o diálogo deve ser considerado como um processo interacional dinâmico voltado para a construção de conhecimentos, torna-se inevitável enfocar os gêneros a partir da interlocução entre autores e teorias que contribuam com saberes importantes para a área.

Como afirma Dolz (2016, p. 15), "dialogar é uma condição para avançar em qualquer domínio social e também no domínio científico”. Na Academia, o diálogo é essencial para que sejam criados vínculos entre pesquisadores que contribuem com os mais diversos posicionamentos para o desenvolvimento de distintos saberes. A pesquisa sobre gêneros é construída a partir de diferentes interpretações dos constructos teóricos e conceituais que levam à reflexão e ao debate constante.

O debate permite intercompreensões dinâmicas que se disseminam e conferem consistência às diferentes pesquisas que podem convergir para a elaboração de concepções teóricas e resultados peculiares e inovadores. Em outras palavras, a pesquisa sobre gênero se orienta por diferentes abordagens e, por esse motivo mesmo, os diálogos são necessários para que se chegue a um desenvolvimento mais expressivo da área. Nesse sentido, os diálogos entre teorias de gêneros também se mostram como sistemas complexos, uma vez que "a reflexão sobre os gêneros sempre lida direta ou indiretamente com o diálogo. Diálogo e dialogismo argumentativo supõem conhecer e reconhecer o pensamento do outro" (DOLZ, 2016, p. 15). Entendemos ainda que as interlocuções entre teorias nos trabalhos analisados devem ser concebidas como plurais, 
na medida em que diferentes processos de recepção de teorias podem ser vistos nesses trabalhos.

\section{Diálogos e sínteses no Nordeste: os estudos de gênero na UFPE e na UFC}

A seguir, antes de apresentar os resultados do estudo, especificamos os procedimentos metodológicos adotados para a construção deste trabalho.

Procedimentos metodológicos

Para os propósitos deste trabalho, empreendemos um recorte de um corpus mais amplo, analisado por Pimentel (2019), que tratou das interlocuções teóricas em estudos de gênero em centros de pesquisa representativos de todo o Brasil. Assim, selecionamos dois centros de estudos sobre gêneros no Nordeste, sendo eles o Programa de PósGraduação em Letras (PPGL) da Universidade Federal de Pernambuco (UFPE) e o Programa de Pós-Graduação em Linguística (PPGL) da Universidade Federal do Ceará (UFC), conforme indicação de Marcuschi (2008) sobre os primeiros centros irradiadores da pesquisa sobre gênero no Brasil.

Para a seleção das 86 teses e dissertações de que trata este estudo, primeiramente fizemos um levantamento dos títulos dos trabalhos de mestrado e doutorado desenvolvidos nos PPGs em tela, no período de janeiro de 2000 a julho de 2016 . Em seguida, selecionamos as teses e dissertações que apresentavam os termos gênero(s), gênero(s) textual(is), gênero(s) de texto, gênero(s) discursivo(s) ou gênero(s) do discurso e algumas que, mesmo não apresentando esses termos, mencionavam um gênero específico no título. Em um terceiro momento, realizamos a leitura dos resumos de cada trabalho, para finalmente chegarmos a uma conclusão sobre quais trabalhos efetivamente se dedicavam à temática de gênero. Foram descartados trabalhos em que 
o termo gênero se referia a gênero social, além de pesquisas em que o gênero (textual/discursivo) era apenas especificado como base para análise de outros aspectos da linguagem, não envolvendo nenhuma teorização sobre gênero para o desenvolvimento do trabalho.

Para os fins deste artigo, consideramos especificamente o resumo como base para a análise, ainda que tenham sido consideradas como fontes complementares, além dos títulos, as introduções, os sumários e os capítulos teóricos do trabalho. Nesse sentido, buscamos identificar indícios de interlocução, a combinação ou confrontação de teorias a partir das referências dos autores a pesquisadores e a teorias de gênero. Para tanto, seguimos os seguintes passos: (a) verificamos que tipo de estudo foi feito nos trabalhos; (b) examinamos que autores serviram como base teórica dos trabalhos e, consequentemente, quais foram as principais teorias de gênero mobilizadas; (c) buscamos identificar eventuais combinações e diálogos teóricos efetivados nos estudos.

No tratamento dos dados, cada trabalho é identificado por uma sigla formada pelos seguintes elementos: T ou D para tese ou dissertação; um número sequencial $(1,2$, 3... 86); e a sigla da Universidade em que o trabalho foi desenvolvido. Por exemplo, para os trabalhos do PPGL/UFPE, temos: T1UFPE, T2UFPE... D1UFPE, D2UFPE e assim por diante.

Estudos sobre gênero no PPGL/UFPE

O Programa de Pós-Graduação em Letras da Universidade Federal de Pernambuco é um dos mais tradicionais do Brasil, o primeiro do Norte-Nordeste, com mais de 40 anos de atividade. O PPG é constituído por duas áreas de concentração, Linguística e Teoria da Literatura. Na área de Linguística, o programa conta com quatro linhas de pesquisa que incluem descrição e Análise estrutural e histórica de línguas, Análises do discurso, Estudos textuais-discursivos de práticas sociais e Análises de práticas de linguagem no campo de ensino. Os aspectos referentes aos estudos sobre gêneros textuais podem ser encontrados em duas dessas linhas, tanto no que diz respeito 
à análise estrutural e funcional de gêneros, quanto à relação entre gêneros e o ensino de língua portuguesa e estrangeira. Uma das áreas a que o Programa se dedicou é justamente o estudo de gêneros. Esse foco nos gêneros se explica principalmente pela presença e influência de Luiz Antônio Marcuschi. O Programa estabilizou-se, no período sob análise, como um importante centro de pesquisa em gêneros também pela quantidade de pesquisadores que formou e que, sob diferentes enfoques, seguiram tratando do tema. Entre vários outros pesquisadores, podemos mencionar Angela Paiva Dionísio, Elizabeth Marcuschi, Márcia Mendonça.

As teses e dissertações analisadas do PPGL/UFPE incluem estudos que fazem tanto análises de gêneros como aplicações de gêneros ao ensino na educação básica e superior. No período de 2000 a 2016, foram defendidos 34 trabalhos dessa natureza, subdivididos em 16 teses e 18 dissertações. Das 16 teses, o6 empreendem análises estruturais, retóricas e funcionais de gêneros e 10 desenvolvem trabalhos aplicados ao ensino no contexto da educação básica e do ensino superior. Quanto às 18 dissertações, 11 fazem análises de gênero e 07 são trabalhos aplicados ao ensino. No todo, os trabalhos envolvem discussões de caráter teórico acompanhadas de análises de gêneros específicos, bem como propostas de ensino, relatórios de experiências em projetos de ensino mediado por gêneros e análises de material didático.

Com o objetivo de investigar quais teorias de gêneros são mais frequentemente utilizadas nas teses de doutoramento e nas dissertações de mestrado do PPGL/UFPE, observamos quais autores foram mais citados e buscamos associar esses teóricos às várias abordagens de estudos de gêneros mencionadas na introdução deste artigo. No Gráfico 1, representamos os autores em que as pesquisas analisadas buscam aporte teórico. É importante ressaltar que elencamos aqui apenas os autores cujas propostas são assumidas como centrais para o trabalho e não todos os autores mencionados, visto que é comum os pesquisadores realizarem uma revisão mais ampla da literatura e citarem teóricos de forma mais geral. 
Gráfico 1: Autores mais utilizados como base teórica ${ }^{1}$ em teses e dissertações no PPGL/UFPE

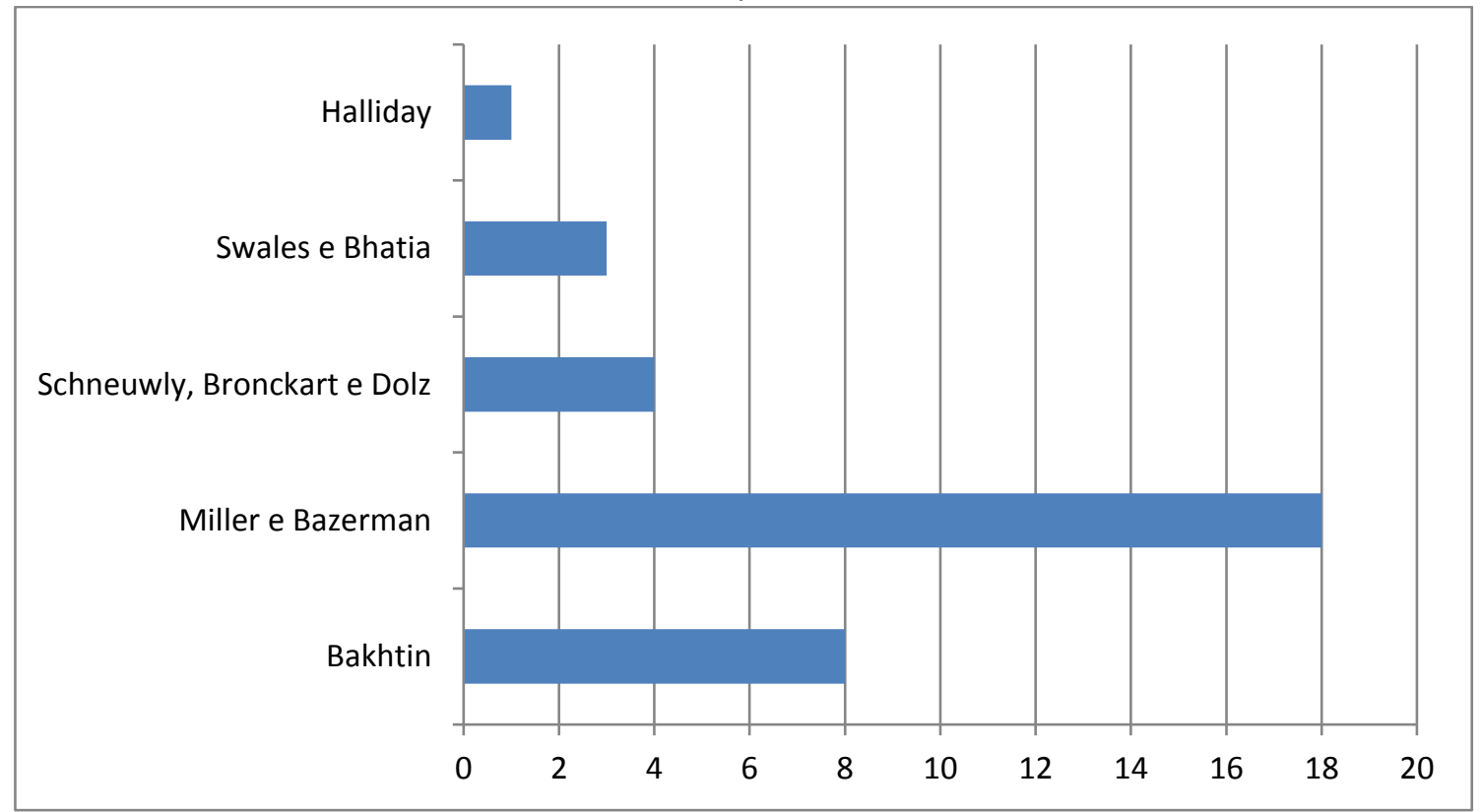

Fonte: Elaborado pelos autores

Como se pode notar, Mikhail Bakhtin ${ }^{2}$ é tomado como autor de base em o8 trabalhos analisados, em diálogo com outros estudiosos. 03 desses trabalhos estão inseridos na perspectiva da teoria dialógica da linguagem e 05 estão ligados à perspectiva do Interacionismo Sociodiscursivo. Os pesquisadores norte-americanos Carolyn Miller e Charles Bazerman, vinculados aos Estudos Retóricos de Gênero, são autores de base em 18 pesquisas. Jean-Paul Bronckart, Bernard Schneuwly e Joaquim Dolz, pesquisadores vinculados ao Interacionismo Sociodiscursivo, aparecem como autores de base em 04 trabalhos. John Swales e Vijay Bhatia, ligados à perspectiva do Inglês para Fins Específicos, são utilizados como base para 03 trabalhos. Finalmente, Michael Halliday, com a teoria da Linguística Sistêmico-Funcional, é autor de base em apenas um dos trabalhos, no qual é feito um estudo sobre a transitividade e a construção de sentido no gênero editorial.

\footnotetext{
${ }^{1}$ Definimos um autor como base teórica para o estudo considerando dois critérios: i) a indicação, pelo autor do trabalho, dessa condição para determinado teórico; ii) o vínculo entre os principais conceitos mobilizados no estudo e a obra do teórico.

${ }^{2}$ Observamos que as menções a Mikhail Bakhtin recobrem citações não apenas específicas a esse autor, mas também a Valentin Voloshinov, mesmo quando os autores não explicitam esse fato. No entanto, a atenção a esse aspecto da autoria das obras "bakhtinianas" fugiam ao escopo deste trabalho.
} 
Dessa forma, a perspectiva mais recorrente que embasou teoricamente a noção de gênero textual adotada nas pesquisas sobre gêneros no PPGL/UFPE foi a dos Estudos Retóricos de Gênero, evocada por 18 de 34 trabalhos analisados. A predominância dos ERG nos estudos do PPG não surpreende se levarmos em consideração a forte difusão local do trabalho de Miller e Bazerman ao longo da década passada, não apenas com a tradução de artigos, ensaios e livros desses autores para o português e a divulgação de entrevistas em mídia audiovisual e escrita (Série Bate-Papo Acadêmico)3, mas também com a presença dos estudiosos em diferentes eventos promovidos, por exemplo, pelo grupo de pesquisa Núcleo de Investigações sobre Gêneros Textuais (NIG). Enquanto esteve ativo na década passada, o NIG mobilizou pesquisadores e estudantes interessados em pesquisas na temática dos gêneros e foi coordenado pela professora Angela Paiva Dionísio, uma das responsáveis diretas pela presença tanto de Miller como de Bazerman na UFPE a partir do ano de 2005. É importante notar ainda que, antes dessas visitas, Angela Paiva Dionísio realizara estágio pós-doutoral com Charles Bazerman na Califórnia, EUA. Charles Bazerman, particularmente, desenvolveu uma expressiva interlocução com Luiz Antônio Marcuschi em eventos locais e no processo de publicação de seus primeiros trabalhos no Brasil. Esse intenso diálogo resultou em uma grande visibilidade e familiarização com a perspectiva dos ERG por parte de mestrandos e doutorandos, motivos que podem explicar sua predominância nas pesquisas realizadas.

Outro aspecto que chamou a atenção, ainda que não captado pelo gráfico, foi a menção aos autores Mikhail Bakhtin e Luiz Antônio Marcuschi na totalidade dos trabalhos analisados, ainda que não se tratasse de adotá-los como aporte teórico central. Com relação ao primeiro, o fato de o pensamento bakhtiniano poder ser tomado como uma espécie de “consenso teórico” nos estudos da linguagem já havia sido apontado por Marcuschi (2008) e retomado em trabalhos como os de Silva e Bezerra (2014) e Bezerra (2016). Quanto a Luiz Antônio Marcuschi, também faz muito sentido ele ser citado em todos os trabalhos, visto se tratar de um pesquisador de renome nacional, professor do Programa e orientador de diversos trabalhos desenvolvidos ali. Além disso, Marcuschi

3 As entrevistas em vídeo podem ser encontradas no canal do NIGUFPE no YouTube: https://www.youtube.com/channel/UCYI84dthIKk6ei7orbROGYg. 
foi um dos pesquisadores pioneiros nos estudos de gênero no país. A recorrência das menções a Marcuschi ainda podem ser explicadas pela abrangência e pela "mestiçagem" (MOTTA-ROTH, 2008) de suas contribuições teóricas, que não se prendem a uma teoria única, mas admitem múltiplas contribuições para o delineamento de uma abordagem mais geral, como afirma o próprio Marcuschi (2008).Segundo classifica Dolz (2016), Marcuschi é um exemplo de pensador brasileiro "autóctone", detentor de uma visão “original” e ao mesmo tempo derivada do diálogo com as teorias de gênero e outras. Nesse sentido, Marcuschi não buscou se associar a nenhuma tradição de estudos de gêneros em particular, mas incluía a si mesmo numa perspectiva mais geral que dialogava com diferentes abordagens. Assim, conforme Bezerra (2016, p. 473), os estudos de Marcuschi parecem deixar clara "a intenção de não se filiar a uma perspectiva única, importada, mas moldar diversas contribuições teóricas combinando-as de modo produtivo para os estudos de língua no país”. Isso fica claro quando percebemos a presença intensa de Marcuschi nas pesquisas analisadas.

Com o objetivo de observar se há diálogo ou articulação entre diferentes perspectivas (sobre gênero e outro aspecto da linguagem), investigamos se, nos trabalhos analisados, outras abordagens teóricas eram mobilizadas ao lado dos autores centrais associados a gênero. Nesse sentido, concluímos que Carolyn Miller, Charles Bazerman e Mikhail Bakhtin foram os autores mais utilizados como base para diálogos entre teorias. Por exemplo, as teorias de Miller e Bazerman foram utilizadas em combinação com os trabalhos de Gunther Kress e Theo Van Leeuwen ou com a obra de Dominique Maingueneau, entre outras possibilidades. Do mesmo modo, o pensamento de Bakhtin foi mobilizado em combinação com as perspectivas de Vijay Bhatia e John Swales ou ainda com a obra de Michael Halliday. Os diálogos perpassam as teorias como um sistema complexo, em diversas direções.

No exemplo a seguir (Figura 1), constatamos a combinação entre as "Teorias da Enunciação" de Bakhtin, Voloshinov e Authier-Revuz e os "postulados das Teorias do Discurso de vertente francesa", representados, no trabalho, por "Brait (1997, 2001, 2005, 2006), Cunha (1992), Possenti (1995, 2001, 2002, 2003), Faraco (2001, 2002) e outros". 
Figura 1: Interlocução entre teorias do discurso rede dialogica que compreende o "seu" discurso e o discurso de outrem. A
perspectiva teórica adotada é a que se pauta pelos trabalhos advindos das Teorias
da Enunciação de Bakhtin (1983, 2000), Bakhtin/Volochinov (1999), Volochinov
(1976), Authier-Revuz (1990, 1998 e 2004) e dos postulados das Teorias do
Discurso de vertente francesa, representados aqui pelos trabalhos de Brait (1997,
$2001,2005,2006)$, Cunha (1992), Possenti (1995, 2001, 2002, 2003), Faraco (2001,
2002 ) e outros. As análises têm evidenciado que a autoria, compreendida como um Fonte: Acervo PPGL/UFPE (T7UFPE) ${ }^{4}$

Entre as muitas interlocuções possíveis, verificadas no corpus, citamos ainda trabalhos que relacionam gêneros à multimodalidade, combinando, assim, postulados de Bazerman e Miller com teorias de Kress e van Leeuwen; um trabalho que combina ERG com a teoria da estrutura retórica; um estudo que apresenta interlocução entre os ERG, a concepção de gênero de Dominique Maingueneau e a análise do discurso de vertente francesa. Dessa forma, nossos resultados corroboram o proposto por Bezerra (2016, p. 467), ao afirmar que "as pesquisas de gênero stricto sensu têm sido conduzidas no Brasil a partir de contribuições dessas abordagens [LSF, ERG, ISD, ESP, entre outras], isoladamente ou em combinações diversas entre si ou com outros aportes teóricos”.

Nesse sentido, destacamos o próximo exemplo, em que a autora alia reflexões sobre as concepções de funções retóricas de Carolyn Miller (ERG) e de propósitos comunicativos de John Swales (ESP) à teoria das tradições discursivas de Johannes Kabatek. Esse trabalho reafirma a riqueza de interlocuções feitas em trabalhos sobre gêneros para que se possa chegar a novas concepções, bem fundamentadas, no campo de estudo, que possam ser utilizadas para explicar o funcionamento dos gêneros.

Figura 2: Interlocução entre teorias de gênero e tradições discursivas forma genérica. Através do fenômeno, os elementos do Cartão Postal Turístico
foram incorporados pelo Cartão Publicitário criando uma nova forma, com funçōes
retóricas (MILLER, 2009) e propósitos comunicativos próprios (SWALES, 2009).
Para que se pudesse observar todo o processo de mudança dos gêneros ao longo
do tempo histórico, a analise foi realizada do ponto de vista diacrónico, aliando a
Teoria dos Generos (BARZEMAN, 2005, 2006, 2007; MARCUSCHI, 2001, 2007,
2008; BAHTIA, 2009) a Tradiçâo Discursiva, conceito da Fillologia Romanica Alemá
(KABATEK, 2003, 2005; ASCHENBERG, 2002; SCHELIEBEN-LANGE, 1983 apud
ASCHENBERGER, 2002). O ponto crucial da análise fol constatar dois fatos:
Fonte: Acervo do PPGL/UFPE (D11UFPE)

${ }^{4}$ A íntegra dos trabalhos se encontra em https://www.pgletras.com.br/acervo.php. 
Como pode ser visto no resumo, a pesquisadora chega ao conceito de "transmutação genérica provocada” a partir dos diálogos entres as teorias mobilizadas. É importante perceber que apenas uma teoria não teria dado conta da complexidade da forma genérica que foi estudada, levando em consideração todos os seus aspectos. Interessante perceber essa formação de um novo conceito que pode servir de base para análise de outras formas genéricas da contemporaneidade, como ressalta a própria pesquisadora.

A Figura 3 apresenta um exemplo em que a pesquisadora constrói um diálogo entre os Novos Estudos de Letramento e as teorias de gênero, conforme evidenciado no resumo da dissertação.

Figura 3: Interlocução entre teoria de letramentos e teorias de gênero

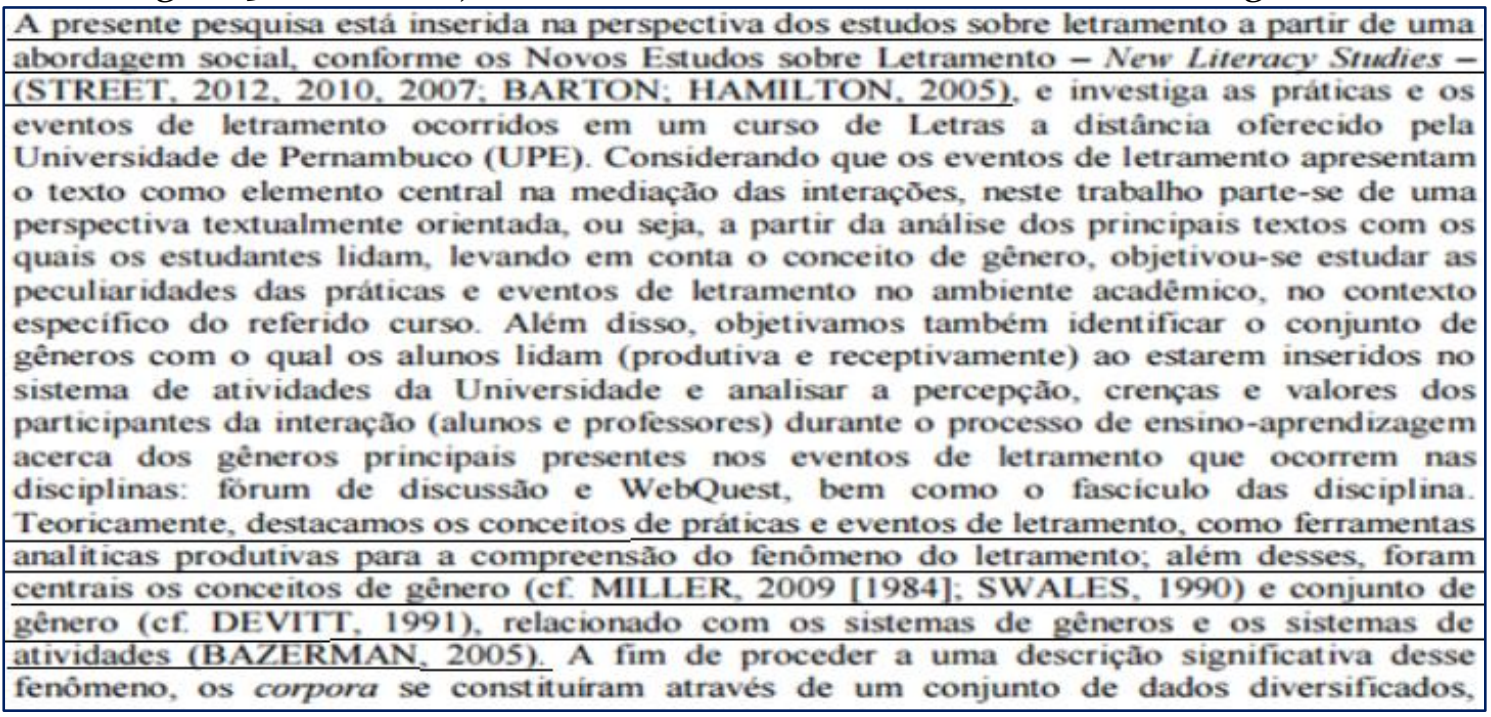
Fonte: Acervo do PPGL/UFPE (D15UFPE)

Em seu trabalho, a autora pesquisa sobre as práticas e os eventos de letramento na educação a distância de nível superior. Assim, ela considera que, ao ingressar em um curso superior, o estudante precisa desenvolver letramentos diversos para obter sucesso em sua carreira acadêmica e profissional, entendendo, portanto, que é necessário pesquisar práticas vigentes no ambiente acadêmico a partir de um conceito de letramento essencialmente plural, visto que as práticas de leitura e escrita na Academia exigem o reconhecimento da necessidade de letramentos múltiplos. 
Para isso, a pesquisadora adota a perspectiva dos Novos Estudos de Letramento em diálogo com os Estudos Retóricos de Gêneros, principalmente no que se refere aos conceitos de gênero, conjunto de gêneros, sistemas de gêneros e sistemas de atividades, e com a perspectiva do Inglês para Fins Específicos para o trabalho com o conceito de gênero em contextos acadêmicos. No trabalho, podemos perceber como a mobilização de conceitos específicos pode contribuir para a construção de um aparato consistente.

Nesse sentido, lembramos o princípio do circuito retroativo da Teoria da Complexidade, pois, mesmo com a ruptura com determinados conceitos das teorias adotadas, na medida em que nem todos os aspectos dessas teorias são levados em consideração, existe um equilíbrio dinâmico organizado por retroações mútuas e que mostra a complexidade na construção de determinados diálogos nos quais os teóricos precisam estar em consonância, principalmente na escrita do pesquisador que os propõe. Desse modo, entendemos que, apesar de as teorias conservarem as suas estruturas essenciais, elas podem adquirir novas propriedades analíticas.

A seguir, veremos como as interlocuções teóricas têm sido construídas no âmbito do PPGL da Universidade Federal do Ceará.

Estudos sobre gênero no PPGL/UFC

Na UFC, os estudos de gêneros também são desenvolvidos com grande força por meio do Programa de Pós-Graduação em Linguística, que funciona desde o ano de 1993. Conforme o regimento do Programa5 , o objetivo principal do PPGL/UFC é oferecer uma formação de excelência com sólido embasamento linguístico aos profissionais que atuem em nível superior como pesquisadores e docentes na área de Linguística. Além deste objetivo maior, a formação do PPGL confere ao profissional a capacidade de prestar assessoria que vise o planejamento e à definição de políticas de ensino de língua materna e línguas estrangeiras.

${ }^{5}$ Informações coletadas em https://ppgl.ufc.br/pt/regulamentos/ em o2 de junho de 2020. 
No Programa, existe apenas uma área de concentração, Linguística, que se desdobra nas seguintes linhas de pesquisa: 1) Aquisição, desenvolvimento e processamento da linguagem; 2) Descrição e análise linguística; 3) Práticas discursivas e estratégias de textualização; e 4) Linguística Aplicada. O PPGL/UFC também conquistou significativa tradição com as pesquisas sobre gêneros, principalmente através de docentes como Bernardete Biasi-Rodrigues, Júlio César Rosa de Araújo, Maria Margarete Fernandes de Sousa, Áurea Suely Zavam, entre outros.

No banco de teses e dissertações da UFC, encontramos um total de 16 teses referentes a estudos de gêneros, no período em foco. Desses trabalhos, og fazem análises de gêneros como chats, editoriais, fofoca, carta, entre outros. 03 pesquisas estão relacionadas com o ensino e desenvolvem relatos de experiências a partir de propostas de ensino-aprendizagem com gêneros de texto. As outras o4 teses caracterizam e descrevem gêneros como, por exemplo, anúncios publicitários. Quanto às dissertações, encontramos um total de 36 estudos que envolvem a temática dos gêneros. São pesquisas bastante diversificadas que se propõem a fazer discussões de caráter teórico seguidas da análise de gêneros específicos, propostas de ensino por meio de gêneros, relatos de experiências com o ensino mediado por gêneros, análises de material didático, entre outras possibilidades. Desses trabalhos, 22 estão ligados ao ensino de línguas, seja estrangeira ou materna, e 14 fazem caracterizações e descrições de gêneros específicos através de diferentes abordagens teóricas. Teses e dissertações totalizaram 52 trabalhos.

No Gráfico 2, são apresentados os autores centrais para esses trabalhos e, consequentemente, a base para os diálogos que comentaremos, analisaremos e exemplificaremos a seguir. 
Gráfico 2: Autores mais utilizados como base teórica em teses e dissertações no PPGL/UFC

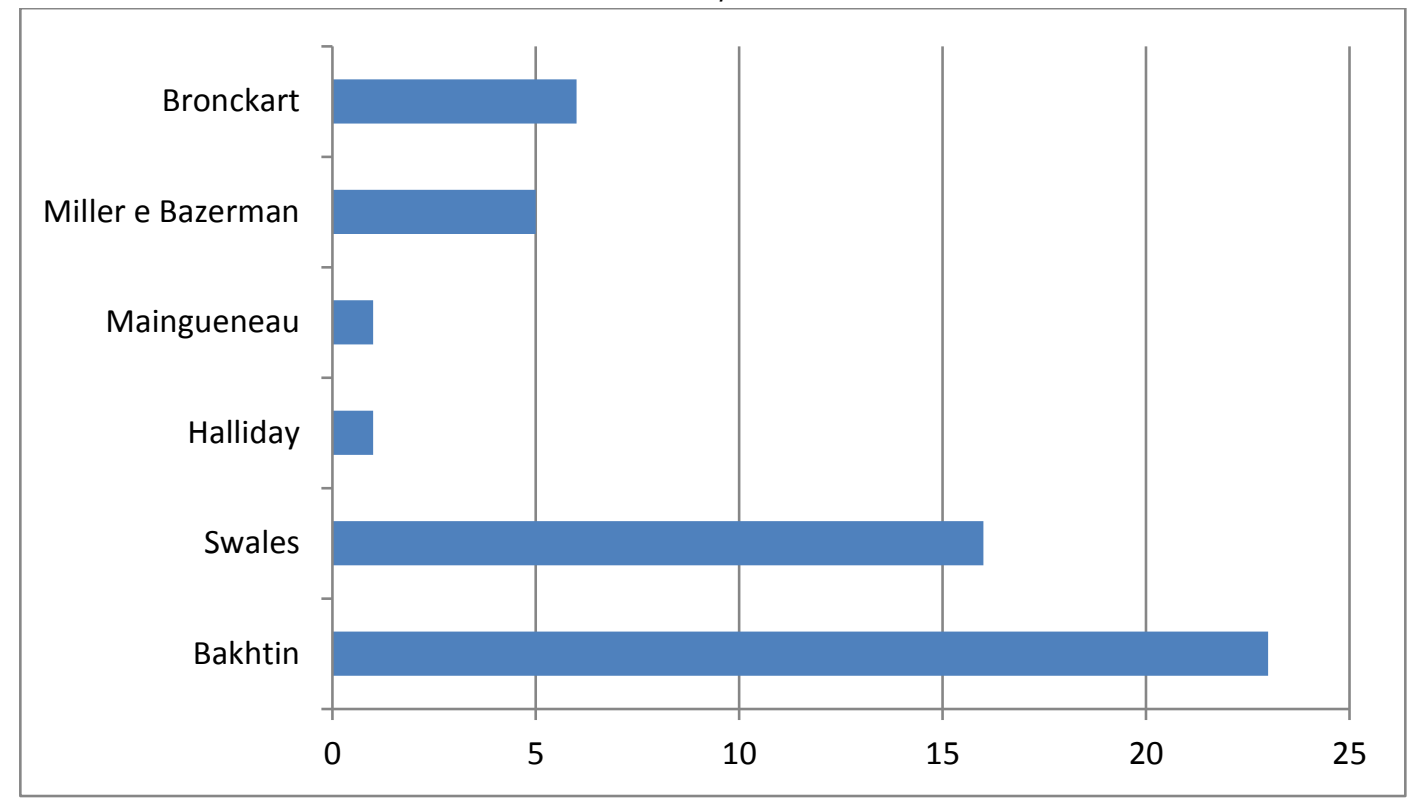

Fonte: Elaborado pelos autores

De acordo com o gráfico, Mikhail Bakhtin aparece como o autor mais recorrente, mencionado em 23 trabalhos como seu principal aporte teórico, seguido de John Swales, que figura como autor principal em 16 trabalhos. A difusão dos pressupostos teóricos de John Swales pode ser explicada pela atuação no PPGL/UFC da professora Bernadete Biasi-Rodrigues, cujas pesquisas tiveram o autor como uma das referências centrais, desde a sua formação na Universidade Federal de Santa Catarina.

Entre os autores que também são citados, encontramos Jean-Paul Bronckart, adotado como a base teórica principal em o6 trabalhos, representando a perspectiva do Interacionismo Sociodiscursivo (ISD), algumas vezes ao lado de Bernard Schneuwly e Joaquim Dolz. Carloyn Miller e Charles Bazerman surgem como figuras centrais em apenas 05 trabalhos, mas também são referência constante em quase todas as pesquisas sobre gêneros no PPG.

Podemos notar, assim, que tanto o PPGL/UFPE como o PPGL/UFC apresentam, nas pesquisas desenvolvidas, interlocuções teóricas bastante frequentes e diversificadas. É importante deixar clara a dinamicidade desses diálogos, ou seja, como os 
pesquisadores sempre se valem de diversos autores para desenvolver suas pesquisas e alcançar os seus objetivos. Percebemos que as principais abordagens de estudo de gêneros, tais como o ISD, ERG, ESP, por exemplo, foram citadas em quase todos os trabalhos. Apesar de existirem autores de base em cada trabalho, os doutorandos e mestrandos sempre constroem interlocuções entre os teóricos em suas pesquisas.

No caso particular do PPGL/UFC, encontramos o diálogo entre a perspectiva da LSF e os aportes teóricos da Análise Crítica do Discurso representada por Norman Fairclough. Nesse caso, ocorre uma combinação das teorias para possibilitar a descrição micro e macrossocial da conversação espontânea (T5UFC). Em outro caso, ocorre o diálogo entre os aportes da LSF e as considerações sobre a retórica intercultural, de Ulla Connor, para fazer um estudo contrastivo da atenuação retórica em artigos de pesquisa (T6UFC). Em ainda mais um trabalho, a teoria sociorretórica de John Swales (ESP) é correlacionada com os princípios de gramática do design visual desenvolvida por Gunther Kress e Theo van Leeuwen (T9UFC). E, finalmente, aportes da Linguística Textual são utilizados, especificamente a noção de sequências narrativas de Jean-Michel Adam, em associação com os pressupostos de Bakhtin sobre gêneros, para analisar o gênero notícia como ferramenta de ensino de língua ( $T_{7} \mathrm{UFC}$ ). Segue-se um recorte de resumo como exemplo dessas interlocuções.

Figura 4: Interlocução entre ERG e Linguística Textual

Nova Retórica. Para a realização desse objetivo, baseamo-nos na concepção de gênero como ação social e de comunidade retórica (MILLER, 2009 [1984]), nas diretrizes metodológicas de análise de gênero (BAZERMAN, 2011a), no protótipo da sequência argumentativa e no plano de texto (ADAM, 1999; 2008), nos tipos de acordo e nas técnicas argumentativas (PERELMAN; OLBRECHTS-TYTECA, 2005). Nosso corpus compõe-se de 100 redações do

Fonte: Acervo do PPGL/UFC (T14UFC) ${ }^{6}$

A proposta da pesquisa consistiu em caracterizar o gênero redação do ENEM a partir da concepção de gênero como ação social segundo Bazerman e Miller (ERG) e desenvolver a análise do gênero sob os aspectos da estrutura composicional textual/discursiva de Adam (2008) e das técnicas argumentativas em Perelman e

\footnotetext{
${ }^{6}$ Disponível em http://www.repositorio.ufc.br.
} 
Olbrechts-Tyteca (2005). Para isso, a autora analisou as características de 100 redações do ENEM de todos os estados da federação que obtiveram a nota mil pelos avaliadores. Essa análise se deu sob a concepção de gênero como ação social, além de ter sido realizada a descrição das categorias de conteúdo temático, construção composicional e estilo propostas por Bakhtin.

Inicialmente, a pesquisadora, além de apresentar a perspectiva de gênero de Bakhtin, concentrando-se nas categorias de estilo, conteúdo temático e construção composicional, adota a abordagem teórica sobre gêneros de Miller e a sua noção de comunidade retórica. Nessa mesma abordagem, adota as diretrizes metodológicas de análise de gêneros de Bazerman, conjunto de gêneros, sistema de gêneros e sistema de atividades, bem como a sua categoria psicossocial para uma compreensão do entorno social do gênero em análise. As teorias de gênero empreendidas fazem diálogo com a teoria de análise textual e de análise do discurso de Adam (2008), com um enfoque na estrutura composicional do plano do texto e do protótipo da sequência argumentativa.

Um segundo exemplo é constituído por uma dissertação que tem como objetivo discutir a literatura referente ao conceito de cadeia de gêneros, apontando pontos de convergências, idiossincrasias e lacunas. Segue-se o resumo.

Figura 5: Interlocução entre perspectivas de gênero e de discurso Esta pesquisa apresenta uma revisão do conceito de cadeia de gêneros desde sua
genealogia em Bakhtin (2000 [1953]) até a discussĩo dos critérios caracterizadores
propostos por Fairclough (2001a [1992]: 2003) e por Swales (2004). Para estes autores, Fonte: Acervo do PPGL/UFC (Di7UFC)

Nesse trabalho, são postos em diálogo conceitos de gênero e de dialogismo de Bakhtin, essenciais para a reflexão do conceito de cadeia de gêneros, e aportes da Análise Crítica do Discurso baseada em Norman Fairclough. Acrescentam-se ao debate as concepções de Swales (2004) também sobre o conceito de cadeias, além de inserir na discussão as ideias de Meurer (2004). O pesquisador justifica trazer Bakhtin para a discussão por pensar que, apesar de nenhuma das discussões sobre cadeias de gênero, cadeias intertextuais e cadeias de práticas terem sido feitas efetivamente pelo estudioso, 
é possível perceber que todas elas, em maior ou menor grau, sejam desdobramentos da sua teoria sobre o dialogismo.

Esse pensamento sobre os escritos de Bakhtin parece ser uma das chaves para a compreensão do motivo por que o filósofo russo está presente em tantos e diferentes trabalhos. Ainda que alguns conceitos específicos não estejam explicitamente ligados aos escritos do autor, estes serviriam de base para a difusão desses conceitos cunhados por autores posteriores, tanto no campo dos gêneros quanto em outras áreas.

Como sugerem os exemplos aqui expostos e discutidos, os diálogos e as interlocuções entre teorias de gêneros textuais são bastante complexos e envolvem diferentes aspectos das teorias, categorias de análise, modos de análise, entre outros, daí procurarmos explicar os dados à luz dos princípios da Teoria da Complexidade.

\section{Considerações finais}

Nosso objetivo, neste artigo, foi investigar como se caracterizaram, do ponto de vista da recepção, apropriação e interlocuções entre teorias, os estudos de gênero em dois programas de pós-graduação situados no Nordeste, analisando teses e dissertações produzidas por eles entre os anos 2000 e 2016.

De modo geral, parece-nos que os estudos de gêneros, nos dois PPGs analisados, mostram uma tendência maior em absorver (com diferentes graus de alteração) e aplicar as teorias existentes no âmbito internacional, havendo iniciativas mais escassas (mas não menos importantes) de teorização própria, a exemplo do próprio pesquisador da UFPE, Luiz Antônio Marcuschi. Apesar disso, a produção nos programas analisados não consiste, apenas, numa reprodução pura e simples das tradições internacionais de estudos de gêneros, existindo confirmações de movimentos de combinação entre aportes teóricos diversos com múltiplas possibilidades, configurando uma tendência para abordagens teoricamente "mestiças", no dizer de Motta-Roth (2008).

Inclusive, os dados sinalizam uma mudança de tendências em relação à leitura feita por Marcuschi (2008) em relação a ambos os programas. A tendência do 
PPGL/UFPE, em termos de estudos de gêneros, moveu-se da "perspectiva mais geral”, a que aludira o autor, para um foco maior nos Estudos Retóricos de Gênero e em perspectivas de inspiração bakhtiniana, seja ela dialógica ou interacionista sociodiscursiva. Já o PPGL/UFC, por um lado, manteve a ênfase nos estudos inspirados em John Swales, como indicado por Marcuschi (2008), porém passou a desenvolver com muita força estudos de gênero sob a concepção bakhtiniana.

A partir do momento em que decidimos pensar os gêneros como fenômenos complexos e os diálogos entre teorias como sistemas complexos, assumimos uma postura de que as perspectivas partem da heterogeneidade, de que as relações aqui apresentadas são extremamente dinâmicas, não lineares, e que as pesquisas, na construção de sua discussão teórica e aparato analítico, em geral, mostravam abertura e adaptação no que se refere a tudo o que envolve o fenômeno dos gêneros textuais. Nesse sentido, seria bastante redutor pensar em apropriação de teorias de modo fixo e uniforme, razão por que desenvolvemos o trabalho sob a premissa de que os diálogos e interlocuções seriam plurais. Assim, é importante discutir os resultados na relação com os princípios da Teoria da Complexidade, buscando compreender sob essa luz os diálogos entre teorias.

Primeiramente, entendemos o princípio dialógico como caracterizador geral do que nos propomos neste artigo. A partir desse princípio, compreendemos a complementaridade das teorias e a indissociabilidade em uma mesma realidade entre o que pode ser pensado como ordem e desordem nas interlocuções.

Em segundo lugar, é importante retomar o princípio da recursão ou recursividade organizacional. Por esse princípio, produto e produtor, causa e efeito interagem na complementaridade de teorias, assim como produtos e efeitos devem ser considerados como produtores e causadores do que se produz, do que é tido como resultado final nas pesquisas.

Em terceiro lugar, lançamos mão do princípio hologramático para explicar que parte e todo devem ser percebidos como uma mesma realidade, visto que as teorias podem ser articuladas em todos os aspectos que a representam, mas também em aspectos que, mesmo pontuais, têm características específicas das teorias a que pertencem. Isso nos leva ao quarto princípio, o do circuito retroativo, através do qual 
percebemos a dinâmica entre continuidade e ruptura, na medida em que alguns pesquisadores utilizam teorias fazendo alterações e adaptações para que atendam da melhor maneira possível aos seus objetivos. Desse modo, essa dinâmica de interlocuções pode evidenciar certa autonomia, mas ela depende do que vamos chamar de "entorno teórico", já que sempre se assenta em outras teorias, que, mesmo mais antigas, são extremamente necessárias à compreensão dos novos paradigmas.

Em último lugar, o princípio da reintrodução do conhecimento no todo do conhecimento, alerta-nos para a questão de que o conhecimento de mundo, seja qual for ele, é sempre uma reconstrução pensada por mentes determinadas por culturas e épocas específicas. Nesse sentido, a dinamicidade dos pensamentos e das relações teóricas são, inevitavelmente, caracterizadas por esses aspectos.

Sob essas luzes, concluímos que os estudos de gênero no Nordeste do Brasil, conforme sinalizado pela produção dos PPGs aqui analisados, efetivamente se caracterizam por inter-relações complexas entre teorias diversas, focadas ou não focadas em gêneros, apropriadas sob as condições históricas e culturais específicas da região. Essa apropriação indicia, por um lado, a relação com aportes teóricos gestados em outros contextos e, por outro, vai caracterizando um modo próprio de lidar com as diversas abordagens e perspectivas de estudo. Muitas vezes, o caminho seguido é não se filiar estritamente a uma teoria específica, e sim buscar apropriar-se do que é cabível em cada uma delas, usar aquilo que melhor serve aos propósitos da pesquisa proposta. Ademais, cumpre observar a frequente vinculação desses propósitos com aplicações concretas dos aportes teóricos adotados, especialmente voltadas para o ensino de língua.

\section{Referências}

ADAM, Jean-Michel. A linguística textual: introdução à análise textual dos discursos. São Paulo: Cortez, 2008. 
BAWARSHI, Anis S.; REIFF, Mary Jo. Gênero: história, teoria, pesquisa, ensino. São Paulo: Parábola Editorial, 2013.

BAZERMAN, Charles. The Brazilian blend. In: LOUSADA, E. G.; FERREIRA, A. D'O.; BUENO, L.; ROJO, R.; ARANHA, S.; ABREU-TARDELLI, L. (Orgs.). Diálogos brasileiros nos estudos de gêneros textuais/discursivos. Araraquara: Letraria, 2016. p. 645-650.

BEZERRA, Benedito G. A propósito da "síntese brasileira" nos estudos de gêneros. Revista de Estudos da Linguagem, Belo Horizonte, v. 24, n. 2, 2016, p. 465-491.

. Gêneros no contexto brasileiro: questões (meta)teóricas e conceituais. São Paulo: Parábola Editorial, 2017.

DOLZ, Joaquim. Prefácio: início de um diálogo necessário. In: LOUSADA, E. G.; FERREIRA, A. D'O.; BUENO, L.; ROJO, R.; ARANHA, S.; ABREU-TARDELLI, L. (Orgs.). Diálogos brasileiros nos estudos de gêneros textuais/discursivos. Araraquara: Letraria, 2016. p. 14-20.

LARSEN-FREEMAN, Diane. Chaos/complexity science and second language acquisition. Applied Linguistics, v. 18, p. 141-165, 1997.

LARSEN-FREEMAN, Diane; CAMERON, Lynne. Complex systems and applied linguistics. Oxford: Oxford University Press, 2008.

MARCUSCHI, Luiz Antônio. Produção textual, análise de gêneros e compreensão. São Paulo: Parábola Editorial, 2008.

MEURER, José Luiz. Ampliando a noção de contexto na linguística sistêmico-funcional e na análise crítica do discurso. Linguagem em (Dis)curso, Tubarão, v. 4, n. esp, p. 133157, 2004

MORIN, Edgar. Ciência com consciência. 11. ed. Rio de Janeiro: Bertrand Brasil, 2008. Para sair do século XX. Rio de Janeiro: Nova Fronteira, 1986.

MOTTA-ROTH, Désirée. Análise crítica de gêneros: contribuições para o ensino e a pesquisa de linguagem. DELTA, São Paulo, v. 24, n. 2, p. 341-383, 2008. Disponível em: http://www.scielo.br/scielo.php?script=sci_arttext\&pid=S0102-44502008000200 oo7\&lng=en\&nrm=iso. Acesso em: 02 jun. 2020. 
PAIVA, Vera Lúcia. M. O.; NASCIMENTO, Milton. Sistemas adaptativos complexos: língua(gem) e aprendizagem. Belo Horizonte: Faculdade de Letras/FAPEMIG, 2011. PERELMAN, Chaim; OLBRECHTS-TYTECA, Lucie. Tratado de argumentação: a nova retórica. 2 ed. São Paulo: Martins Fontes, 2005.

PIMENTEL, Renato L. Diálogos, caracterização e contribuições dos estudos de gêneros em teses e dissertações no Brasil. Recife. 2019. Tese (Doutorado em Letras) Universidade Federal de Pernambuco, Recife, 2019.

PIMENTEL, Renato L.; LÊDO, Amanda C. O. Gêneros textuais e ensino: diálogos entre teorias de gênero em teses e dissertações na UFPE. In: LOUSADA, E. G.; FERREIRA, A. D’O.; BUENO, L.; ROJO, R.; ARANHA, S.; ABREU-TARDELLI, L. (Orgs.). Diálogos brasileiros nos estudos de gêneros textuais/discursivos. Araraquara: Letraria, 2016. p. 3447 .

SILVA, Noadia I.; BEZERRA, Benedito G. O conceito de gênero em artigos científicos sobre ensino de língua materna: repercussões de quatro tradições de estudos. In: APARÍCIO, A. S. M.; SILVA, S. R. (Orgs.). Gêneros textuais e perspectivas de ensino. Campinas, SP: Pontes Editores, 2014. p. 17-48.

SILVA, Xênia S. O gênero textual cartão publicitário: um estudo da transmutação genérica. 2011. Dissertação (Mestrado em Letras) - Universidade Federal de Pernambuco. Recife, 2011.

SWALES, John M. Research genres: exploration and applications. Cambridge: Cambridge University Press, 2004.

VIAN JR., Orlando. Beyond the three traditions in genre studies: a Brazilian perspective. In: ARTEMEVA, N.; FREEDMAN, A. (Ed.). Genre studies around the globe: beyond the three traditions. Winnipeg: Inkshed, 2015. p. 95-114.

Recebido em 14/o7/2020.

Aprovado em 31/o7/2020. 